BULLETIN Bulletin hispanique

HISPANIQUE Université Michel de Montaigne Bordeaux

$111-2 \mid 2009$

Varia

\title{
Adriana de González Prad
}

migrante y escritora

Isabelle Tauzin-Castellanos

\section{(2) OpenEdition}

Journals

Edición electrónica

URL: http://journals.openedition.org/bulletinhispanique/1042

DOI: 10.4000/bulletinhispanique. 1042

ISSN: 1775-3821

Editor

Presses universitaires de Bordeaux

\section{Edición impresa}

Fecha de publicación: 1 diciembre 2009

Paginación: 623-638

ISBN: 978-2-86781-617-8

ISSN: 0007-4640

Referencia electrónica

Isabelle Tauzin-Castellanos, « Adriana de González Prad », Bulletin hispanique [En línea], 111-2 | 2009,

Publicado el 01 diciembre 2012, consultado el 01 mayo 2019. URL : http://journals.openedition.org/

bulletinhispanique/1042 ; DOI : 10.4000/bulletinhispanique.1042 


\title{
Adriana de González Prada : migrante y escritora
}

\author{
IsABELLE TAUZIN-CASTELLANOS \\ Université Michel de Montaigne - Bordeaux
}

L'article analyse le témoignage d'Adriana de Verneuil - González Prada sur les voyages qu'elle effectua entre la France et le Pérou (1875-1898). Touriste involontaire et auteur méconnu, elle devint une immigrée par la force des circonstances. Il s'agit de déconstruire ici le récit autobiographique pour ébaucher une histoire féminine des mobilités entre l'Amérique et l'Europe à la fin du XIXe siècle, distinguer l'étape des préparatifs, la diversité des moyens de transport et l'altérité perçue sur les lieux d'escale. Le témoignage expose une anti-conquête des deux mondes, typique peut-être du nomadisme féminin.

El presente artículo tiene como punto de partida el testimonio de Adriana de Verneuil de González Prada sobre los viajes que hizo entre Francia y Perú (18751898). Turista involuntaria y autora desconocida, se convirtió a la fuerza en migrante. Se trata de deconstruir el relato autobiográfico para esbozar una historia femenina de los desplazamientos entre América y Europa al final del siglo XIX, identificar los preparativos, la variedad de los medios de transporte y la alteridad descubierta en las escalas. El testimonio expone una anti-conquista de los dos mundos, tal vez representativa del nomadismo femenino.

This article will analyze the account given by Adriana de Verneuil-González Prada of the travels she made between France and Peru (1875-1898). An unvoluntary tourist and an underrated writer, she became an immigrant by force of circumstances. We will here deconstruct the autobiographical story in order to sketch a women's history of mobility between America and Europe at the end of the 19th Century. The step of packing up, the diverse means of transport, the otherness perceived in the places where she called at, all those points must be distinguished. This account puts forward a 'counter-conquest' of both worlds, a trend typical, perhaps, of women's nomadism.

Mots-clés : Adriana de González Prada - Pérou - XIXe siècle - Histoire des transports - Identité féminine.

BHi, Tome 111, n² 2 - décembre 2009 - p. 623 à 638. 
$\mathrm{L}$

A VIDA de Adriana de Verneuil, esposa y biógrafa del ideólogo peruano

Manuel González Prada, está siendo redescubierta. La complejidad de sus memorias justifica plenamente esta atención ${ }^{1}$. Un siglo después de Flora Tristán cuyas peregrinaciones entre París y Lima (1833) desconocía como la inmensa mayoría de sus contemporáneos, Adriana de González Prada resucitó por la escritura todas las etapas de su existencia de migrante, desde la salida de Francia en 1875 hasta el regreso definitivo al Perú en 1898.

Mi Manuel, grueso volumen de más de cuatrocientas páginas, fue escrito tardíamente, entre 1938 y 1940, pero se ciñe al orden cronológico, desde el nacimiento de Verneuil en 1865 hasta la muerte de González Prada en 1918. Como lo señala Beatriz Colombi, «toda escritura viajera es un lugar de convergencia y dispersión de saberes: fuga de un centro y profusión temática son sus características más constantes ${ }^{2}$ ». Mi Manuel es una suma de narraciones que evitan la repetición, prueba del trabajo de composición de la autora; sin embargo, las anécdotas se hacen eco mutuamente, dada la variedad del itinerario de Verneuil.

Para valorar su texto sin parafrasearlo, el presente trabajo desarmará el periplo de la esposa de González Prada, interesándose primero en los preparativos. Después de lo cual será analizada la percepción del desplazamiento a caballo, en tren o en barco. Por último, me dedicaré a sintetizar las estadías por ciudades y países que resultaron cada vez menos asombrosos para Adriana, vuelta perita en viajes.

\section{Preparativos}

La literatura peruana tiene entre sus páginas de antología el cuadro de costumbres de Felipe Pardo y Aliaga: «Un viaje» (1840). El escritor costumbrista pone en escena a un cincuentón ridículo que tarda medio año en alistarse antes de viajar a Chile. Esa demora increíble distingue «a muchos de la generación actual», a diferencia del autor comprometido en muchas revoluciones y que se autodefine como «el mueble más liviano y más portátil ${ }^{3} »$. De forma muy parecida Adriana de Verneuil cuenta la brusquedad de su partida de Francia. Estamos en 1875 y la niña de diez años es todo un estorbo para su padre, recién enviudado y que reorganiza su vida en función

1. Véanse los artículos señalados en la bibliografía.

2. B. Colombi, Viaje intelectual. Migraciones y desplazamientos en América latina (18801915), Rosario, Viterbo, 2004, p. 18.

3. Felipe Pardo y Aliaga, Teatro completo. Critica teatral. El espejo de mi tierra, Lima, PUCP, 2007, p. 735-736. 
del hijo casi adulto. Se ve «llevada como un paquete que trasladan, sin siquiera consultar su propia voluntad ${ }^{4} »$. La decisión de no dejarla al cuidado de una parienta, resulta irreflexiva: «En el último momento no había tenido valor de separarse de mí: ese sencillo y repentino arranque cambió todo el rumbo de mi vida» (ibid). El trío se marcha a Inglaterra de donde pasa a los Estados Unidos y al Perú, a invitación de un viajero conocido al azar, Luis Faustino Zegers, secretario del magnate de los ferrocarriles, Henry Meiggs.

La falta de preparación va a ser la constante de este viaje inicial, previsto para durar dos meses y que se convierte en éxodo definitivo, cuando están agotados los recursos económicos del padre:

me explicó creer serle ya difícil volver, por haber cambiado todo su dinero francés en soles peruanos y seguir muy bajo el cambio sobre París (52).

Migrante a pesar suyo, Adriana tiene que ingresar como interna al colegio de Belén. Allí es víctima del escarnio ajeno y se ve tachada de «gringa, gabacha, [y] franchuta [...] pensando regresar a Francia, mucho antes de que se cumpliera tan largo transcurso de tiempo» (48).

En cambio, Alfredo, el hermano, vuelve a París para vender la casa familiar. Es la figura del actante oponente, responsable involuntario de la muerte de la madre; asumirá el cargo de tutor al morir el padre, pero las relaciones entre hermanos no serán nunca de complicidad.

Para Adriana se suspende la vida nómada por más de quince años, hasta el retorno en 1891, casada con Manuel González Prada. Entonces sucederá el segundo gran viaje que durará nada menos que siete ańos. Adriana elude el tema de los preparativos de ese periplo. Apenas se entera el lector de que la venta de la casa familiar posibilita la salida del Perú; así se cumple la voluntad del escritor aunque contraría a sus partidarios:

Al recibir ese dinero Manuel en el acto pensó realizar el deseo que acariciaba desde años atrás de ir a conocer Europa, pareciéndole la mejor oportunidad para hacerlo (166).

Adriana sólo expone de forma alusiva las emociones contradictorias que la invaden, «algo de pena» (177) junto con el ansia de regresar a Francia, y el deseo no escrito de dar a luz en la tierra natal, después de sufrir la muerte de dos nińos recién nacidos. Justifica el dilema interior por la vanidad ante el éxito de Manuel, «en esos alucinantes momentos de visible simpatía hacia

4. A. de González Prada, Mi Manuel, Lima, Cultura Antártica, 1947, 28. Todas las citas remitirán a esta edición. 
[el fundador de la Unión Nacional]» (166). Interpreta el estado de ánimo del líder político; legitima la partida por la voluntad expresa del pensador y no por algún antojo femenino: «Manuel, por el contrario, iba a realizar la ilusión de su vida [...] respirar en fin en ese ambiente de civilización del que se quería saturar» (177). No obstante, el segundo viaje se parece a un desarraigo, a diferencia del primero que lo tuvo todo de aventura novelesca modelada por la literatura infantil. Expone enfática: «Nuestra vida se orientaba ya hacia otros mundos y habría que olvidar lo que dejábamos atrás» (179).

Antes de la partida a Europa, los amigos suben a bordo del buque para una última comida y despedida amenizada por discursos, brindis, «abrazos, lágrimas [y] fervientes votos» (ibid). El Maestro acepta dejarse fotografiar antes de marchar y el hermano de Adriana entrega a ésta una foto para que lo conozca su sobrino. Los retratos cumplen una función simbólica de sustitución del ser ausente. Adriana desempeńa el papel de intercesora en ambos casos; ella aparece como un ser transparente cuya foto a solas figura apenas una vez en las memorias.

El estado de salud y las condiciones climáticas son factores determinantes para emprender un viaje. La decisión de marcharse después de residir cuatro años en París estriba en la salud de Alfredo. Adriana ya ha superado el temor a la muerte de su hijo. En varias ocasiones insiste en la robustez del niño, verdadero sosiego después de los traumas de la muerte de dos recién nacidos y el recuerdo de la pérdida de la madre y la hermana:

Partimos por la gare d'Orléans, contentos, alegres los tres, con nuestro muchacho ya de cuatro ańos, sano, fuerte, encantados de la vida, ricos de nuestro carińo, tesoro que nadie nos podía quitar (220).

De hecho, una epidemia de viruelas causará la postergación de la visita a Madrid, y el temor al invierno provocará el regreso a Burdeos con clima más templado.

Cuando Adriana precisa las circunstancias de un viaje, hace hincapié en el sentimiento de liberación que experimenta luego de vender los muebles acumulados en los ańos de permanencia en París. Reanudan con la vida itinerante:

Íbamos a andar el mundo, libres, descansando donde se nos ocurriera, sin más itinerario, que nuestro antojo y deseo del momento (ibid).

Más adelante se definirá como «ociosa turista [...] ansios[a] de seguir [la] vida errante, cogid[a] por ese afán de ir adelante». El silencio acerca 
de los preparativos sin duda se explica por la diligencia de alguna criada invisibilizada, como se deduce de la evocación de una estadía en Bélgica:

Avisada la víspera nuestra sirvienta por un telegrama, tuvimos el agrado de llegar a nuestra casa y encontrar la mesa puesta, la comida lista y no tener más que sentarnos cómodamente a comer. Qué agradable nos fue: solamente lo puede apreciar el que ha hecho vida de hotel, donde a pesar de todas las comodidades, nunca puede igualar las de su propio hogar (215).

Por tanto, los preparativos no constituyen una molestia. Adriana otorga mayor relevancia a los viajes en sí, como liberación de la rutina y momento de plenitud para la pareja desembarazada de los compromisos con familiares y amigos. La decisión de emprender el regreso resultará difícil, ya que se tratará de renunciar a "vivir en esa comodidad de la vida de viajero, sin tener que preocuparse de los pequeños detalles del hogar algo odiosos, a pesar de su aparente insignificancia» (289). De esa confesión y pese a la ayuda de una empleada doméstica, se deduce la labor indecible, cotidiana y desvalorada de la dueña de casa.

Con todo, a diferencia del personaje inventado por Felipe Pardo y Aliaga, el Niño Goyito a quien rodean un sinfín de personas, Adriana no convierte la etapa de los preparativos en cúmulo de obstáculos: lo importante es viajar y pintar las impresiones del recorrido que han quedado grabadas en la mente.

\section{LOS MEDIOS DE TRANSPORTE: CABALLOS, TRENES Y BARCOS}

En momentos de la guerra franco-prusiana de 1870, la familia de Adriana quiso refugiarse en París huyendo de la avanzada del ejército alemán. El éxodo no se concretó: dejaron de circular los trenes y «los caballos no quisieron arrancar». Hubo que albergar a los oficiales vencedores. Desplazarse a caballo era inseguro. Años más tarde, después de una noche en barco, Adriana y Manuel recorren seis leguas hasta una hacienda al sur de Lima. Ella rememora con precisión una suma de detalles negativos en el tramo, «el fuerte calor», los «largos callejones polvorientos», «una sed loca» y «el agua sucia de la acequia». Además, un toro embiste la comitiva a caballo y terminan por llegar a la casa «bastante triste y desmantelada» (169). Tal frustración se explica por la vida en la urbe a la que Adriana se ha acostumbrado desde la llegada a Lima, contrasta con el «entusiasmo al contemplar los algodonales y yucales que le recordaban [a Manuel] sus tiempos de chacarero en Mala» (171). 
Al emprender el regreso, una caída pone en peligro la vida de Adriana:

Mi bestia empezó a brincar [...] me agarré fuertemente de la silla sujetando las riendas, pero un gran sacudón me arrojó al suelo. En el acto sentí fuertes dolores pero nada dije [...] Dolores más fuertes y otros síntomas alarmantes me hicieron temer un serio accidente. Llamado un médico [...] me prohibió embarcarme, mandándome reposo absoluto (172).

El texto es alusivo; la adjetivación ("gran», «fuertes», "alarmantes») y las repeticiones traducen la viveza del recuerdo. Lo que Verneuil teme es un aborto natural; el embarazo recién empezado forma parte de lo indescriptible.

Cada medio de transporte presenta inconvenientes y ocasiona momentos de confusión. La autora evoca el viaje en tren por Inglaterra: el padre de la niña no se percató de cómo los ferroviarios separaron algunos vagones y el tren partió con los hermanos a bordo solos y desesperados, en un país extrańo. La confusión de sentimientos, el miedo y la alegría del reencuentro se transparentan en el relato de Adriana: "Al verlo [a mi padre], volví a llorar, pero de alegría esta vez, besándolo y abrazándolo, loca de gusto, después del gran susto que me había pegado» (30).

Otro incidente sucedió a los pocos días pues los tres franceses se equivocaron entre dos convoyes y hubieron de pasar la noche a la intemperie, en una estación vacía antes de desandar lo andado y llegar a Liverpool. Adriana justifica el error por los usos ingleses: «Es preciso conocer lo que es una estación de ferrocarriles en Inglaterra, para darse cuenta de lo fácil que es equivocarse de tren y así nos pasó» (31).

Ahora bien, el viaje en tren tiene la ventaja de permitir breves etapas. Cuando los González Prada deciden marcharse de París, eligen detenerse en muchas ciudades para visitarlas. El lugar donde albergarse reviste especial importancia. Después de nombrar los hoteles de París donde estuvieron por un par de días, la autora apunta su preferencia por las casas de huéspedes con público selecto:

Recibían solamente personas de aspecto respetable y [...] nos dieron una guía para cada ciudad. Ningún letrero avisaba al transeúnte y solamente recibían al que fuera portador de una especie de tarjeta de reconocimiento (222).

El sentido de la intimidad, la preocupación por la higiene y la moralidad se manifiestan con vehemencia y son decisivos a la hora de elegir dónde pernoctar:

La casa de muy buen aspecto, limpia y decente nos agradó más que la asquerosa cama del mejor hotel, aún cálida del último ocupante de la noche anterior. (Ibid) 
Viajar da la oportunidad de conocer los últimos progresos, como la luz eléctrica que se enciende y apaga por ensalmo en el hotel, aunque la viajera franco-peruana no se interesa en absoluto por las técnicas. Los ferrocarriles españoles serán blancos de su crítica, tanto por la lentitud como por lo ineficaz del sistema de calefacción. El testimonio se hace más veraz con la interpolación del discurso ajeno:

Llegamos a Irún, límite de la frontera con Francia. Allí tuvimos que cambiar de tren, por ser de vía angosta los de España: «Por temor de que los franceses invadan sorpresivamente nuestro territorio», nos dijo muy seriamente uno de los empleados (284).

La presencia de un nińo despierta la curiosidad de los pasajeros y favorece la conversación. Sirve de "trait d'union para ligar amistad entre personas desconocidas» (239) aun cuando el trío se basta a sí mismo.

Franquear la aduana sucede sin dificultad. Trátese de un pasajero catalán que suelta una palabrota o una aragonesa que deja escapar camarones en el compartimento, los detalles tragicómicos reemplazan el síndrome del abandono del viaje inicial por Inglaterra.

Difiere mucho la percepción del paisaje en tren en el primer viaje a América y en el regreso a Europa. La narradora recuerda cuál fue su asombro al descubrir la selva en el trayecto Colón-Panamá. La realidad coincidía entonces con el mundo de Robinson Crusoe, el modelo por el que aceptara viajar con la promesa paterna de tener un mono y un loro. Lírica, rememora primero las impresiones sensoriales que la asaltaron en la contemplación de la naturaleza, «esa fertilidad asombrosa, esos enjambres de enredaderas abrazadas de los árboles alcanzando sus más altas ramas, los famosos cocoteros $[. .$.$] naranjos y limoneros cubiertos de flores y frutos a la vez»$ (39). Concluye como reviviendo la emoción del momento: «Fue realidad lo soñado, pude palpar, hasta comer estas frutas tropicales tan provocativas». Pero lo que no estaba en la ficción y en que se fijó la niña por empatía, fue en los cuerpos desnutridos de los niños:

Con sus barrigazas enormes que parecían el centro vital de sus seres, con sus piernas enclenques y sus cabezas diminutas, se alineaban desnudos para ver pasar el tren (ibid).

De forma global son breves las descripciones de paisajes entrevistos en tren y coinciden con los clichés sobre tal o cual lugar. Normandía, la región francesa de donde sale el tren de Cherburgo a París, es recordada a través de la mirada de Manuel, el esposo que descubre Francia. Adriana traduce las impresiones que imagina en él, "admirado" ante "los fértiles campos de 
Normandía, célebre por sus manzanos, ya cuajados de flores y sus praderas donde pastaban tranquilas vacas» (183), un paisaje verdísimo del todo opuesto a «la extraña aridez de la costa del Perú, donde no se veía un solo árbol» (41) como observara al llegar en 1875. Desde la ventanilla Cataluña presenta un rostro laborioso adornado de «altas chimeneas de las fábricas industriales» (253), inconfundible con la miseria del campo de Castilla:

Muy pobres aparecían los lugares que atravesábamos, tanto la campiña como el aspecto general de sus aldeas, semejando nidos de topos sus chozas, cobadas $[$ sic $]$ en la tierra y hasta de su mismo color (255).

Ese dualismo traspasará de alguna manera en la prosa de Manuel González Prada que teorizará sobre las dos Espańas, la tradicionalista y la republicana 5 .

Si el viaje en tren anticipa el descubrimiento de un país gracias a las imágenes fugaces desde la ventanilla y los intercambios con los pasajeros que suben y bajan en cada estación, la experiencia del barco es muy distinta. Para Adriana las travesías del Atlántico y el Pacífico reconstituyen de forma provisoria un hogar, con una casa que lleva nombre, el nombre del vapor o del paquebote ${ }^{6}$ en que se permanece varias semanas: Wisconsin, Acapulco, Aconcagua... La huérfana se integra entonces a una nueva familia cosmopolita y variada con un pasaje distinto en cada escala.

En la primera etapa a Nueva York, no hay otro niño; el padre se entretiene con los demás pasajeros. Adriana se ve rodeada de artistas que cantan ópera, juegan y organizan sesiones de espiritismo en las que toma parte proporcionando el valioso material de una mecha de cabello. Algunos extranjeros llaman la atención por lo excéntrico, como un general nicaragüense calificado de «anfibio» y "arco iris ambulante» por el «fárrago de uniformes múltiples y multicolores» (38) o el general Echenique que exige "pastelillos de ruibarbo» (41). En el tramo Panamá-Lima, Adriana se reúne con otros nińos de modo que juntos se convierten en «los verdaderos dueños del barco, paseándo[se] y correteando por todos los lados, sin dejar de escudrińar un solo rincón» (40). No obstante, aquella travesía le ocasiona una suma de experiencias traumatizantes y explicables por el desamparo vivido al lado de un padre aquejado por una forma de parálisis: de genio audaz, Adriana no

5. Véase Manuel Suárez Cortina «Laicismo y anticlericalismo en la España de fin de siglo: Manuel González Prada y las dos Españas», en I. Tauzin, Manuel González Prada: escritor de dos mundos, Lima, IFEA, 2006, 69-98.

6. El anglicismo está registrado en el diccionario de la Real Academia con el significado de transporte de viajeros a partir de 1884 . 
respeta las prohibiciones y va a contemplar el mar enfurecido. La tormenta es tal que regresa asustadísima al camarote. También es víctima del afán del ex presidente Echenique en peinar su larga cabellera, un «martirio» que la marea hasta que llega a escapar del cepillo.

En el regreso a Lima de 1898, el motivo de escarnio es una venezolana «coquetona y muy elegante» que se hace depilar por el médico de a bordo y se insinúa en la vida del oficial desencadenando un episodio tragicómico (295). En ese viaje Adriana entabla relaciones amistosas con las hijas del gobernador de Martinica, huérfanas de madre como lo fuera Adriana en tiempos del viaje en el Wisconsin; las muchachas la ven como compañera y se le acercan:

Se afanaban en sacarme de noche a pasear con ellas en la cubierta, no concibiendo que yo prefiriera quedarme tranquilamente sentada al lado de Manuel (291).

Adriana se enfrenta a una disyuntiva, entre la distracción con los demás viajeros y la compañía de su esposo, mientras que en la ida a Francia, la joven pareja formaba un todo unido y «el carácter retraído y concentrado de Manuel no daba lugar a muchos acercamientos con los demás pasajeros» (180). Aquel viaje en barco de 1891 se pareció a una tardía luna de miel en que la pareja disfrutó plenamente del apartamiento de los familiares. El exotismo de la comida inglesa servida a bordo y despreciada por los demás pasajeros poco propensos a las novedades, fue un anuncio de los descubrimientos que iban a hacer al arribar al Viejo Mundo. En varios momentos asoma el tema de la comida, expresión de un hedonismo y placer de vivir que Verneuil desea compartir con los demás, preparando en Madrid un perol de manjar blanco que le vale los aplausos de los huéspedes y los celos de la dueńa (279).

En el vapor, el tiempo estaba como suspendido. Verneuil no apunta la duración de las travesías, aunque señala la competencia salvaje entre las compañías. En los viajes de ida y de vuelta, la pareja perdió las conexiones y tuvo que transar para conseguir otros boletos, una molestia frecuente a la que alude brevemente. Otra peripecia fue el encallar del barco en la isla de Barbada: "Con gran suerte no pasó de un susto» (182).

La travesía en compañía del pensador peruano iba dominada por los diálogos políticos. Las amistades efímeras y privadas importan poco ante la primacía de la acción pública. Así es como la pareja conoce primero al liberal ecuatoriano Eloy Alfaro exiliado en Panamá, y luego a Behanzín, el rey de Dahomay confinado en Martinica. Hasta se alegran de haber perdido una conexión y no coincidir a bordo con Nicolás de Piérola, blanco de la sátira pradiana. En el regreso al Perú, Manuel conversa con Felipe Pardo, hijo del 
escritor costumbrista, mientras que Adriana recibe las confidencias de unos muchachos llevados como reclutas por los franciscanos que aprovechan el deseo de las madres de salvar a sus hijos de la guerra en Cuba. Con empatía se apiada de los jóvenes a los que baja a visitar en tercera mientras que los frailes, instalados en primera, forman un batallón sobrealimentado y ocioso que le repugna profundamente ${ }^{7}$.

Hasta el regreso a Lima de 1898, Adriana es la protagonista de Mi Manuel. Después de llegar al Perú, la narradora cede el primer plano y en adelante se contenta con un rol segundario, con Manuel y Alfredo en los papeles principales de la saga familiar. En momentos de arribar, la curiosidad del primer viaje a América se ve reemplazada por un sentimiento ambivalente, entre alegría y vergüenza, tanto más que Adriana vuelve con un hijo y lo mira todo con otros ojos. Comenta desengańada:

Volvíamos a ver con gusto por ser el terruño, el lugar donde se formó nuestra vida, aun la mía, a pesar de ser francesa. [...] Era realmente chabacano y humillante ver esa multitud de lanchitas sucias y oír sus llamadas intercaladas de interjecciones groseras, en su lucha de conseguir pasajeros para llevarlos a tierra (302-303).

El retorno es definitivo. Ya no viajará la autora desde 1898 hasta los años 20. Adriana descartó el relato de esas otras peregrinaciones y se concentró en la recreación de los viajes de su juventud. Preparativos y desplazamientos no tienen sentido si no se llega a algún destino. Después de estar en tránsito, en tierra de nadie, por mar o en tren, hubo la etapa del descubrimiento de otros espacios y pueblos diferentes.

\section{Algunos apuntes SObRe las ESCALAS y ESTAdíAs}

La autora de Mi Manuel evoca sucesivamente Inglaterra, Estados Unidos, Centroamérica, Perú, Ecuador, Venezuela, Francia, Bélgica y España. No todos los países reciben la misma atención; algunos lugares corresponden a simples escalas; otras veces la etapa se convierte en estadía y hasta en paradero definitivo en el caso de Lima.

Los Verneuil y luego los González Prada vivieron en un tiempo sin medición, sin prisa, como aristócratas o rentistas cabales. Ninguna obligación determinaba el momento de irse. La curiosidad por conocer nuevos

7. Estas «catervas de frailes» serán recordadas por González Prada en el ensayo de Horas de Lucha titulado con ironía «Nuestros inmigrantes». 
horizontes era la que decidía la partida después del primer alejamiento de Francia motivado por la muerte de la madre de Adriana.

En Inglaterra, padre e hijos asumen el status de turista, una vida sin horarios, "de continuo paseo» opuesta a la austeridad del colegio donde se crió la nińa hasta los diez años. Lo primero que advierte Adriana, es el «confort inglés desconocido en Francia» (29) «Confort» y "turista» son anglicismos incorporados al español y al francés con los progresos del siglo XIX. La familia Verneuil se dedica al callejeo por las calles de Londres, Birmingham y Liverpool. Contemplan «los edificios más interesantes» (30), visitan los museos y algunas fábricas textiles propiedades de un amigo del padre, a veces se extravían por las «calles enmarañadas». Sólo asoma una crítica imprecisa hacia «el espíritu inglés tan independiente y egoísta a la vez» (32), pero el balance es positivo de modo que el trío decide continuar su periplo hasta América.

En Nueva York los viajeros residen en un hogar para artistas de Broadway. Admiran Central Park pero desisten de ir a las cataratas del Niágara que los prospectos publicitarios hacían «relucir a los ojos de los inocentes turistas» (36). Adriana se acuerda del «derroche de dinero gastado a manos llenas con esa prodigalidad americana que resaltaba cuanto más a los ojos del extranjero, acostumbrado a la parsimonia europea» (35), una crítica severa que coincide con la de otros viajeros contemporáneos como Sarmiento y Martí (Colombi, 2004: 32-35) pero a diferencia de aquéllos, la autora no rememora el tipo de la «mujer nueva», ni lo evoca desde el pasado reciente, 1938, cuando empieza precisamente en Nueva York la redacción de Mi Manuel. Más adelante se asombra ante el boato de una fiesta organizada por Henry Meiggs:

Allí pudimos palpar la verdad del dicho francés: riche comme le Pérou, según el lujo y derroche de cuanto vimos allí dilapidar: quedaría chiquito el cuerno de la abundancia pintado en sus armas para contener todo el oro gastado en esos tres días [...] me parecía vivir los cuentos de las Mil y una Noches al ver esos suntuosos banquetes, bailes campestres, seguidos de fuegos artificiales despampanantes (46).

La prosperidad falaz y el clima de eterna primavera son las causas de la instalación en el Perú de los Verneuil. Es probable que el padre de Adriana esperara así recuperarse de la parálisis, pero el lector no está informado en ningún momento de qué tipo de actividad o negocio maneja Alfredo de Verneuil en Lima.

Adriana se esmera en dar amenidad a la narración de sus viajes y reproducir la ingenuidad de la niña al llegar a Colón y ver por primera vez unos negros. Cuenta que fue «algo asustada por las caras simiescas de ese espécimen 
de la raza humana» (38), una animalización brutal que traduce la visión dominante ${ }^{8}$. Con Alfredo de seis ańos, revivirá divertida aquella primera confrontación: "Alfredito [estuvo] muy preocupado en saber si el rastro de los negros labios de Behanzín no había quedado estampado en su mejilla. Trabajo nos costó tranquilizarlo» (293).

En el paso por el istmo centroamericano observa la mezcla de razas, "la variedad en el color de la piel de cada uno de sus habitantes» (39) y se indigna ante otras tradiciones religiosas al reparar en la catedral de Panamá en «angelitos que parecían bailarines de ópera bufa, con sus trajes cortos y una pierna levantada» (ibid). La representación de la Iglesia se merecería todo un estudio dada la cantidad de apuntes a lo largo de Mi Manuel.

La visión de la población indígena no inspira extensos comentarios, probablemente porque no armoniza con la imagen propalada por los libros de aventuras a la que se enfrenta al regresar a Francia:

me preguntaron si al volver Manuel a su país usaría otra vez el vestido nacional. Dos veces me hice repetir la pregunta antes de comprender que era un modo disimulado de saber si aun se vestían con plumas en el Perú (278).

En cambio, Adriana rememora a los chinos en momentos de arribar a Lima por primera vez: «En otro bote pasaron también unos extraños hombrecitos amarillos y nos dijo don Faustino: -Son chinos, hay muchos en el Perú, traídos como esclavos» (43). La mirada de asombro hacia el Otro es muy sugerente. Creemos que se puede relacionar con la afirmación de Julie Watson citada por Giovanna Minardi (2006: 55): «El sujeto femenino siente mucho la relación con otros en una existencia interdependiente».

En Mi Manuel, Verneuil no busca lo pintoresco; las descripciones de lugares ocupan un espacio muy reducido; los cuadros de costumbres son igualmente escasos y limitados a unas pinceladas (las tradiciones navideńas, los serenos, los toreros...). Ni costumbrismo ni tipismo, esas formas narrativas que confluyen en la guía de viaje según Colombi (2004: 116), organizan el relato autobiográfico. La referencia a monumentos y a museos es breve como imprescindibles paradas en Europa. En cambio, tanto en el Perú adonde llega como nómada antes de convertirse en migrante, como en España, donde los González Prada se asientan por un par de años, Adriana se fija en las mujeres.

8. Marcel Velázquez Castro ha analizado el horizonte racista en que convive Adriana en «La cultura afroperuana en los ensayos de Manuel González Prada», en I. Tauzin, op. cit., 2006, 99-116. 
Le interesan especialmente aquellas que no coinciden con el modelo femenino inculcado en la primera infancia a través del ejemplo materno. Recuerda cómo la vestimenta de las limeñas le llamó la atención al divisar por primera vez a las tapadas:

Me dejó sorprendida la rara moda de manto negro, parecido a aquel con que pintan a las mujeres santas, acompañando a Jesús, al pie de la cruz (43).

Sońó con llevar ese atuendo que iba a desaparecer por los años 1870 reemplazado por la moda europea. Con llaneza cuenta cómo se disfrazó

A escondidas de mi papá para que no se riera de mí, me envolvía en mi amplio waterproof traído de Londres y me miraba en el espejo, para ver como me quedaba el cucurucho que me formaba en la cabeza, encantada de monear la extrańa moda peruana (47).

Al poco tiempo se vio obligada a vestir el uniforme del colegio de Lima, lo que equivalía a entrar en las órdenes y renunciar a la identidad. En un hotel de Biarritz, junto a Manuel indiferente a los esmóquines y vestidos de gala, se complace en "lucir las lindas toilettes que traía de París» y que se habían quedado sin estrenar por llevar una vida "completamente familiar y sencilla" (231-232).

El relato del viaje a Espańa revela la mayor atención a la mujer de a pie. Primero, la esposa de González Prada lamenta la explotación que sufre en una pensión de Barcelona la hermana de la dueña. Se fija también en los requiebros de los huéspedes hacia una brasileña dotada de «bigotes tan frondosos que cualquier gendarme se los podía envidiar» (245). La caricatura delata una exasperación que desemboca en una verdadera rińa conyugal. Rememora otra escena de seducción en una pensión madrileña hasta que ella misma se molesta contra los graciosos y comenta para sí misma: "es increíble lo fácil que es engañar a las pobres cincuentonas» (280). Afirma que junto con la política y los toros, el enamoramiento es el «eterno tema de todo cerebro espańol [...] siendo el sexo su punto vital, la obseción [sic] constante, su primera razón de ser» (258).

La autora se acuerda de cómo se cayó en plena rambla y se enojó ante los piropos de los testigos «lúbricos como verdaderos salvajes, en lugar de ayudar [la] a levantar, como lo habría hecho cualquier hombre en la última aldea del mundo civilizado» (249). Verneuil señala las relaciones de dominación tan patentes en la península como en el Perú. Observa a las costureras que trabajan para la dueña de la pensión, se acomoda entonces junto a una ventana 
que da al taller con el fin de presenciar las conversaciones manteniendo las distancias sociales, y a la vez es vigilada por Manuel que «desde el comedor podía oír lo que hablábamos sin intervenir» (266).

Al regresar a Francia se percata de la connivencia entre los hombres, cierta «mańosa reserva [...] guardándose secreto, tapando sus fechorías» (289). Explica la decisión del regreso de forma escueta como consecuencia de la petición de los amigos y partidarios desde el Perú. No invoca ninguna necesidad material como podría ser la falta de dinero después de siete años fuera.

$\mathrm{Al}$ arribar por segunda vez al Perú, su mirada se confunde con la de su hijo que pisa por primera vez el suelo peruano: «La primera impresión fue de extrañeza al ver los pisos bajos y los techos planos de las casas, acostumbrados a las alturas de las de Europa» (304). En adelante, la presencia de Alfredo orientará la existencia de Adriana: "La voz de mi hijito me hizo volver a la realidad; desheché $[s i c]$ mis tristezas, pensé que con él y Manuel llevaba yo la Felicidad» (290).

Todos esos detalles son nimios, propios de la vida cotidiana elevada al mismo nivel que las experiencias del ideólogo peruano. La valoración de la esfera privada tal vez explique la oposición de Luis Alberto Sánchez ante la publicación de un testimonio que en el fondo iguala a marido y mujer: parodiando el refrán, en Mi Manuel, tanto vale Adriana como Manuel.

Según el biógrafo aprista, la esposa de González Prada estuvo nuevamente en los Estados Unidos en 1924 con motivo del casamiento de Alfredo; después de lo cual, volvió al Perú y se encargó de educar al hijo natural de éste. Viajó a Francia con ambos en 1933 y luego con la sola compañía de una empleada peruana, residió en Nueva York hasta 1944, fecha en que retornó a Lima. Murió en 1948, meses después de publicar sus memorias. Sobre esas imprecisas andanzas el único testimonio que se pueda esperar sería la correspondencia de Adriana si se la llegara a ubicar.

Al fin y al cabo, para Verneuil, viajar no fue nunca conquistar ni dominar sino asombrarse ante lo desconocido e incomprensible. Mi Manuel nos ofrece el relato de una anti-conquista, una especie de narración etnográfica ya conforme con el orden social del Viejo Mundo, ya inconforme con las violencias de género aceptadas por el discurso ideológico dominante.

Analizar los viajes en Mi Manuel desemboca en una frustración. ¿Cómo explicar el silencio sobre los desplazamientos posteriores a 1918, después de la muerte de González Prada? 
Por ser la esposa de un hombre público, en los albores del siglo XX, Adriana enmudece, disimula su propia identidad y opaca esa singular energía y la audacia tan visible en la primera parte de las memorias, hasta el retorno al Perú.

Otra explicación del enmudecimiento es que Verneuil aceptara el destino de migrante: el regreso a Lima pone fin a lo que fue un destierro, un tránsito, aquella llegada improvisada a los diez años. De modo que la autora asume otra nacionalidad: la de su esposo.

Cuando la viuda de González Prada se instala a los sesenta ańos en Nueva York, la mudanza se explica tanto por acercarse a su hijo como por las persecuciones de que es víctima el APRA, el partido político que convirtió a Manuel en Mesías. El regreso definitivo a Lima ocurrirá en el momento de la transición democrática, muerto Alfredo y ocupada Francia por los nazis.

La autora de Mi Manuel resulta una figura ejemplar del nomadismo femenino con esa capacidad de recrear su residencia infinitas veces. Esta deterritorialización la relaciona con muchas otras escritoras, con «el sujeto que ha renunciado a toda idea, deseo o nostalgia por una posición fija [...] Su identidad [es construida] en un devenir hecho de transiciones, mutaciones y permutaciones» (Medeiros-Lichem: 2007, 535).

\section{BiBLIOGRAFÍA}

Chenot Beatriz, «De una orilla a otra: perspectivas francesas en el testimonio de Adriana de González Prada», I. Tauzin-Castellanos, Manuel González Prada, escritor de dos mundos, Lima, IFEA, 2006, p. 31-43.

Colombi Beatriz, Viaje intelectual. Migraciones y desplazamientos en América Latina (1880-1915), Rosario, Viterbo, 2004.

Fernández Bravo Alonso, y Garramino Florencia, Sujetos en tránsito: inmigración, exilio y diáspora en la cultura latinoamericana, Madrid, Alianza, 2003.

González Prada Adriana, Mi Manuel, Lima, Cultura Antártica, 1947.

Medeiros-Lichem Maria Teresa, «El sujeto nómada y la exploración de la memoria en La travesía de Luisa Valenzuela», en Sara Beatriz Guardia, Mujeres que escriben en América Latina, Lima, CEMHAL, 2007, p. 531-538.

Minardi Giovanna, «Mi Manuel de Adriana de González Prada, una mujer francesa y peruana», en Emilia Perassi y Susanna Regazzoni, Mujeres en el umbral. De la iniciación femenina en las escritoras hispánicas, Sevilla, IluminacionesRenacimiento, 2006, p. 54-64.

Rojas Benavente Lady, «Mi Manuel y/o la legitimización autobiográfica de Adriana de González Prada», en Márgara Russotto, La ansiedad autorial: formación de 
la autoría femenina en América latina: los textos autobiográficos, Caracas, 2006, Equinoccio, p. 343-353.

Sánchez Luis Alberto, Nuestras vidas son los ríos... Historia y leyenda de los González Prada, Lima, UNMSM, 1977.

Suárez Cortina Manuel, «Laicismo y anticlericalismo en la España de fin de siglo: Manuel González Prada y las dos Españas», en I. Tauzin-Castellanos, Manuel González Prada, escritor de dos mundos, Lima, IFEA, 2006, p. 69-98.

Szurmuk Mónica, Mujeres en viaje: escritos y testimonios, Buenos Aires, Aguilar, 2000.

Tauzin-Castellanos Isabelle, "Adriana de Verneuil: memorias de un olvido», en Sara Beatriz Guardia, Mujeres que escriben en América Latina, Lima, CEMHAL, 2007, p. 187-200.

Velázquez Marcel, «La cultura afroperuana en los ensayos de Manuel González Prada», en I. Tauzin-Castellanos, Manuel González Prada, escritor de dos mundos, Lima, IFEA, 2006, p. 99-116. 